\title{
Power Electronic Interfaces for Low Voltage Residential Networks
}

\author{
E D Zacharis*, A M Cross*, B Godfrey ${ }^{\dagger}$ \\ * Department of Electrical Electronic and Power Engineering, \\ Aston University, Aston Triangle \\ Birmingham B4 7ET, UK \\ Tel.: +44 (0)1212043731 \\ E-Mail: zachared@aston.ac.uk \\ ${ }^{\dagger}$ Western Power Distribution, \\ Pegasus Business Park \\ Derbyshire, DE74 2TU, UK \\ Tel.: +44 (0) 1332827447 \\ E-Mail: bgodfrey@westernpower.co.uk
}

\section{Acknowledgements}

The authors gratefully acknowledge the financial support received from EPRSC and Western Power Distribution, UK.

\section{Keywords}

$\mathrm{AC} / \mathrm{AC}$ converter, Distribution of electrical energy, Cooling, Power quality, Conduction \& switching losses

\begin{abstract}
A proposal to increase the existing residential LV grid voltage from $230 \mathrm{~V}$ to $300 \mathrm{~V}$ has been made in order to increase existing network capacity. A power-electronic AC-AC converter is then used to provide $230 \mathrm{~V}$ at each property. The equipment can also provide power-quality improvements to the network and load. Several constraints such as temperature rise at the converter location lead to a converter design requiring very high efficiency. In this paper different $\mathrm{AC} / \mathrm{AC}$ converter topologies are presented which compares the power quality benefits, size and efficiency of each converter. The design and the control technique of the most suitable topology are verified using simulation and preliminary experimentally results of prototype hardware are also included.
\end{abstract}

\section{Introduction}

An issue arising in the modern load profile is the growth of electrical energy demand; in LV circuits this is set to continue significantly with an increasing deployment of electric appliances, electrical vehicle charging and the use of electro-heat as an alternative to gas/oil heating. Whilst the use of embedded generation such as photovoltaic units will offset this load to some extent, there will be a considerable strain on the existing LV distribution network. In addition these new loads and associated PV units will exacerbate power quality problems [1-2].

One solution to the problem of limited capacity has been proposed by Western Power Distribution, who are the Distribution Network Operator (DNO) for the Midlands, South Wales and the South West in the UK and this consists of increasing the LV network phase voltage from $230 \mathrm{~V}$ to $300 \mathrm{~V}$. To demonstrate this the typical mains and service cable losses have been calculated for a 100 residence load, for a range of cable run lengths and for different LV network step-up voltage ratios, and these 
results are shown in Figure 1. For example for the proposed 300/230 step-up ratio the cable losses are reduced by around $40 \%$., which provides an opportunity to significantly increase the network capacity. A device is then required at each residence to reduce the voltage back down to $230 \mathrm{~V}$. A likely location for the equipment is next to the meter in the property's meter box as shown in Figure 2a. Due to the various constraints that this environment presents, a traditional wound transformer would not be viable due to its excessive size, weight, losses and acoustic noise. Therefore this project is looking at a power electronic AC-AC converter as a likely solution to this problem. However, in order to prevent temperature rises within the meter box from affecting the electricity meter unit and rating of the main fuse, the converter must have extremely low converter losses.

The use of a power electronic converter can also provide a potential opportunity for improving the power quality of the distribution network as well as the consumer. In addition, the inherent highvoltage DC-link of the converter may be used to couple DC equipment within the house such as PVarrays and EV charging. Alternatively, EV chargers could conceivably couple directly to the $300 \mathrm{~V}$ AC supply using a dedicated connection.

The converter must be capable of bidirectional operation in order to accommodate generation within the property, and have a nominal rating of $15 \mathrm{~kW}$ continuous.

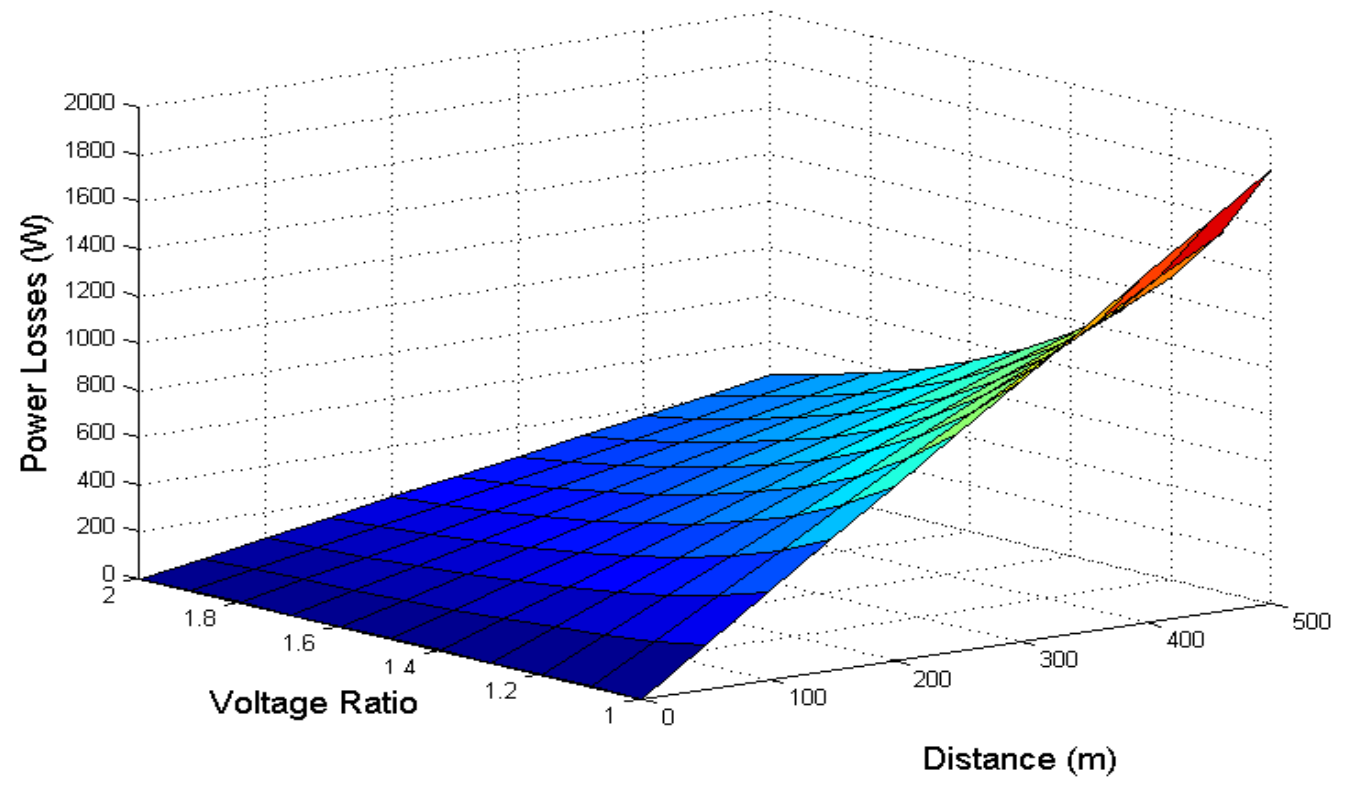

Figure 1: Typical cable power loss (W) for 100 house load against cable distance (m) and step-up voltage ratio

In order to assess the economic viability of the proposed solution against the conventional method of reinforcing the existing network, an estimate of the cost of upgrading a two hundred house section of the network and its associated substation equipment was carried out. This upgrade consists of replacing and re-jointing the main and service cables, which are usually underground, and replacing the transformer, ring-main unit and protection at the local distribution substation. An estimate of the cost of such reinforcement works out at around $£ 570$ per house based on an average mix of rural and urban environment - this will vary to some extent between different DNOs. In urban areas the cost of reinstatement of roads and footprints would be much higher than this average value making a power electronic converter solution more competitive. In addition, these costs do not include the secondary benefits of the electronic converter solution such as improved power quality, reliability and flexibility, nor the ability to stress the existing cables above the proposed $300 \mathrm{~V}$. 


\section{Converter Heat Dissipation}

The converter unit will be located in a customer's meter-box, as shown in figure $2 \mathrm{~b}$. Cooling for the converter is by natural ventilation, as fans are not allowed in the design due to reliability concerns. The requirement for natural ventilation is a serious issue as the converter heat loss is directly into the meter box where both the main fuse and electricity meter have a typical maximum operating temperature of $50{ }^{\circ} \mathrm{C}$. This drives the converter design to one with extremely low losses. Such highefficiency converters are now becoming a practical reality with the availability of SiC switching devices. For example, a 40kVA multilevel inverter prototype has recently been reported [3], which utilises SiC JFETs, and the power density of this converter is comparable to the requirements for this project.

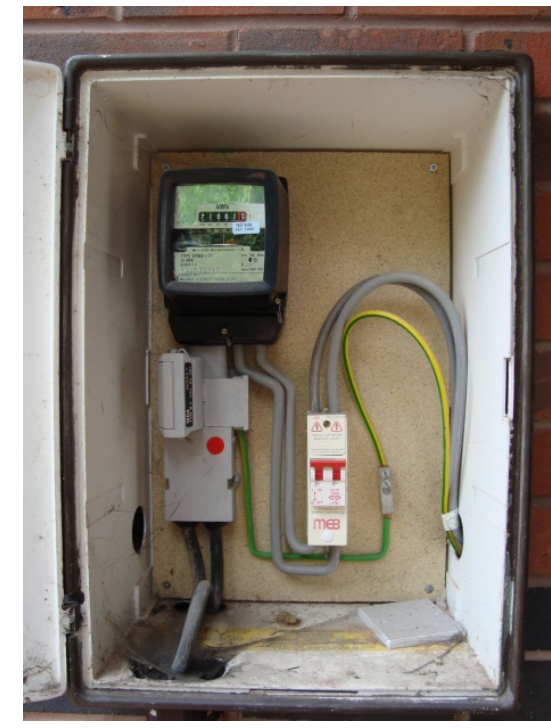

(a)

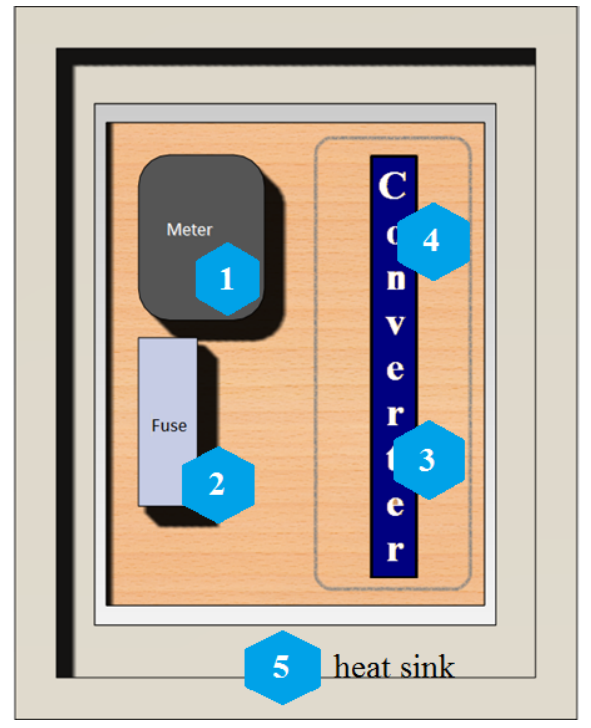

(b)

Figure 2: (a) Meter box and (b) proposed converter location with placement of thermocouples for experimental tests

To quantify the affect of converter dissipation on the temperature rise within the box, several experiments were undertaken for various cooling scenarios. Thermocouples were placed at strategic points with the meter box as shown in Figure $2 \mathrm{~b}$ to measure temperature rise, and power resistors were used to represent the losses from the converter semiconductor devices. The power resistors were mounted on aluminium plates of various shapes and sizes, for example an aluminium door was tested as shown in Figure 3a, as well as aluminium surfaces in L-shapes - Figure 3b, where one face of the L was situated on the inner side of the box, and the other face was exposed to the outside, flush with the door. The scenarios that were considered were:

1. L - shape $\mathrm{Al}$ (40mm outer width)

2. $\mathrm{L}$ - shape $\mathrm{Al}(100 \mathrm{~mm}$ outer width)

3. Al door - converter mounted on inside face of door

4. As (3) but door thermally insulated on the inside face (excluding converter mount)

5. As (4) but additional insulation covering the outside of the converter

6. As (3) with eight ventilation slots cut into the door in front of the meter location 
Figure 4 shows the temperature rise above ambient against converter power dissipation an arbitrarily chosen scenario (5).

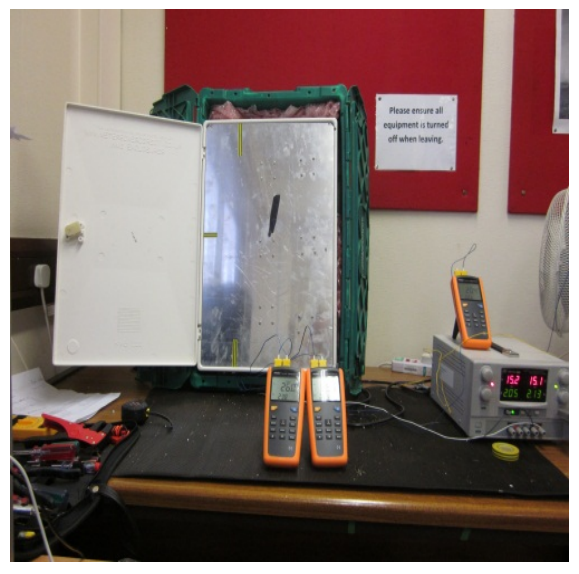

(a)

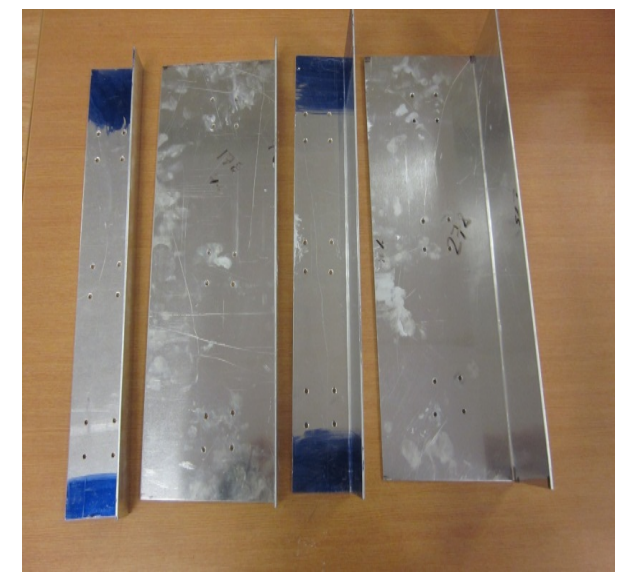

(b)

Figure 3: (a) Al door and (b) L-shape Al surfaces

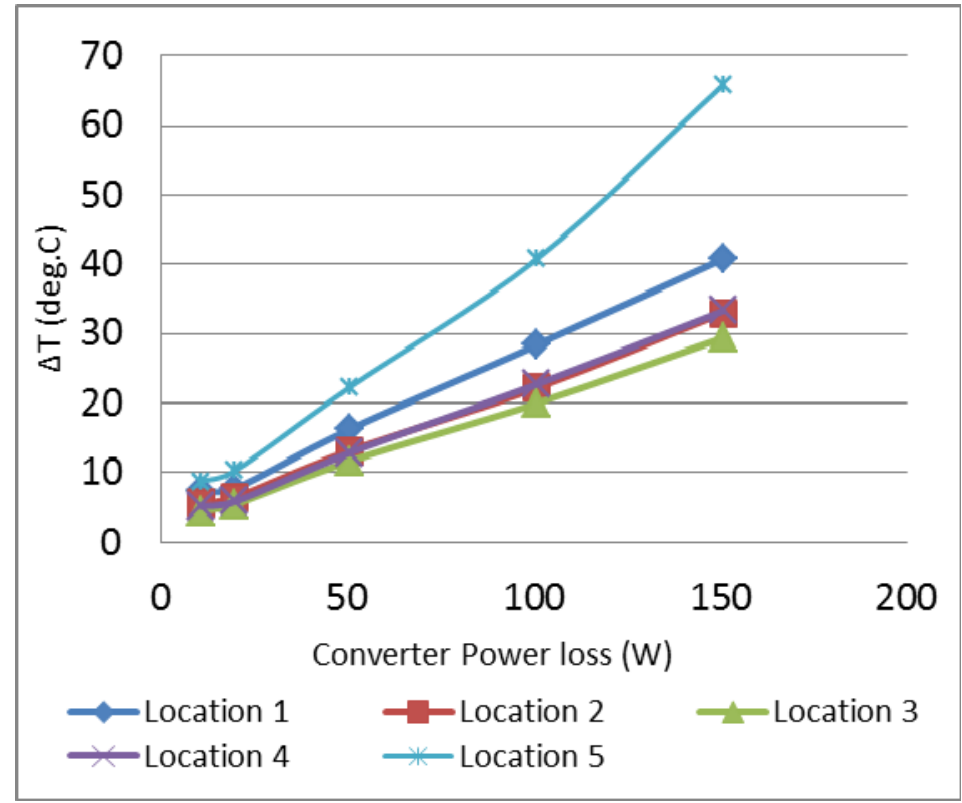

Figure 4: Temperature rise above ambient $\left({ }^{\circ} \mathrm{C}\right)$ inside meterbox against converter power loss $(\mathrm{W})$ for scenario 5 (locations are shown in Figure 2(b))

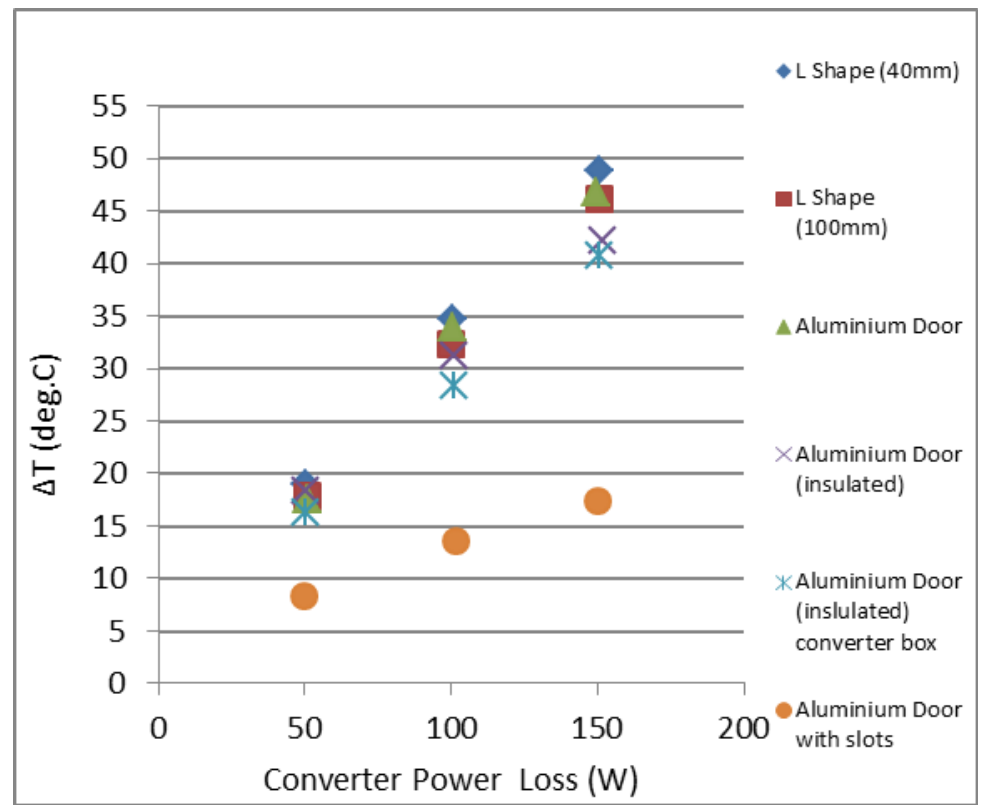

Figure 5: Temperature rise above ambient $\left({ }^{\circ} \mathrm{C}\right)$ against converter power loss (W) for location 1 , for scenarios (1-5)

Figure 4 shows that there is an almost linear rise in temperature with converter dissipation, with the hottest location being next to the meter (location 1). This was also true of all the scenarios (1-6), and a plot of the temperature rise for the most sensitive location - the meter, location 1 against converter dissipation is shown in Figure 5 for all of these scenarios. 
It can be seen form Figure 5 that for the unventilated scenarios (1-5), the aluminium door with insulated converter (5), gives the lowest temperature rise across all of the five scenarios. Under this scenario, in order to keep the internal temperature of the meter box below its maximum value of $50^{\circ} \mathrm{C}$, with say an ambient of $30^{\circ} \mathrm{C}$, the maximum converter loss must be less than approximately $50 \mathrm{~W}$. However, if ventilation slots are used the allowable power dissipation increases be around a factor of three for the same temperature rise. This scenario is quite promising as is it will allow a higher relaxation on the converter's power dissipation to approximately $150 \mathrm{~W}$. However, this would then impact on the Ingress Protection (IP) code of the meter box and additional work will need to be carried out to assess the effect of louvers and/or mesh coverings for the vents on the IP rating, which is currently IP54.

\section{Potential Power Quality Improvements}

There are various opportunities for power quality improvement in the LV network for both the utility (supply) and customer (load) if the proposed converter is deployed within the LV network:

\section{Utility benefits:}

- Removal of load current harmonics from the supply

- Tightly regulated load voltage allows relaxation of limits on supply side voltage variation

- Fundamental power factor improvement

\section{Customer benefits:}

- Removal of supply voltage harmonics from the load

- Tightly regulated load voltage can prevent customer voltage sags, swells and flicker

- Fault ride-through if sufficient converter energy-storage is available

Whilst the primary objective of the converter is to provide a voltage step-down function, many of the AC-AC converter topologies that are being studied as part of this project inherently provide power quality improvements as a secondary benefit. The following section presents various candidate circuits that have a voltage step-down capability as well as discussing their power quality performance.

\section{Candidate topologies}

An ideal topology would appear to be the traditional back-back converter shown in Figure 6, operating with sinusoidal PWM. This converter provides bi-direction step-down capability with all the power quality benefits outlined above, namely unity input power factor, a regulated, sinusoidal output voltage, and the potential for fault ride-though if the DC- link is augmented by an energy storage device.

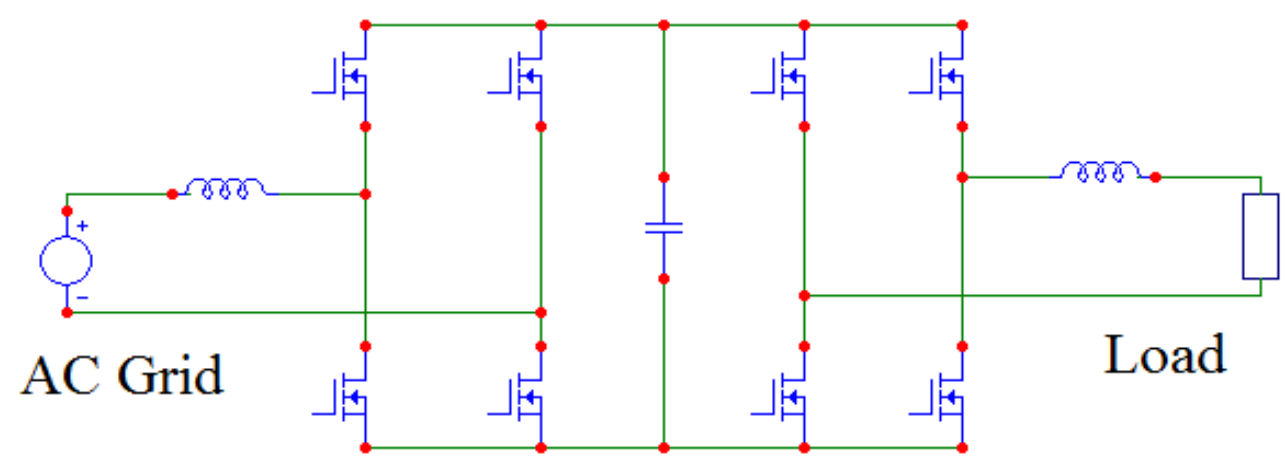

Figure 6: Back-back AC-AC converter. 
However, the efficiency of this converter is very poor due to the cascaded nature of the input and output bridges. In addition, for safety reasons and to maintain the operation of existing protection devices in the house, the converter must provide a direct connection between the supply and load side neutrals, which the above converter does not provide. Therefore an additional isolated DC-DC converter would need to be inserted into the DC-link to allow this connection to be made, which further reduces the converter efficiency [5]. Therefore this converter is not considered for further study.

Two more candidate topologies are shown in Figure 7 and 8 and are termed the Two-Leg and ThreeLeg converters respectively. These have a lower number of semiconductor devices in comparison with the back-to-back converter whilst maintaining the same power quality benefits $[6,7]$.

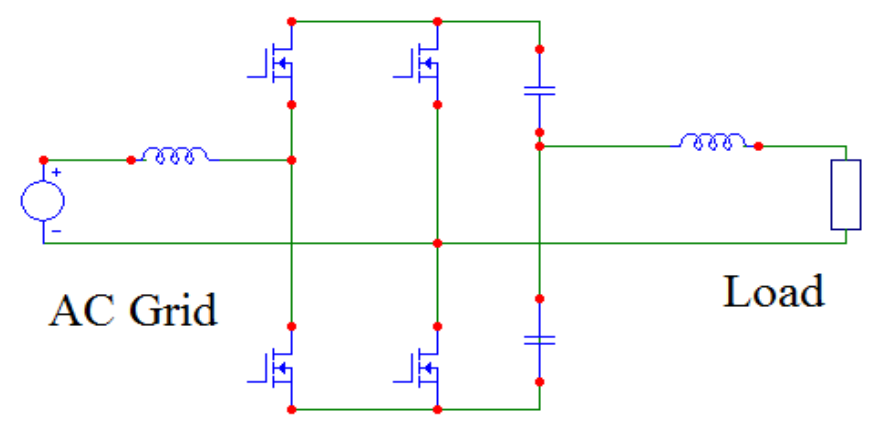

Figure 7: Two-leg AC-AC converter

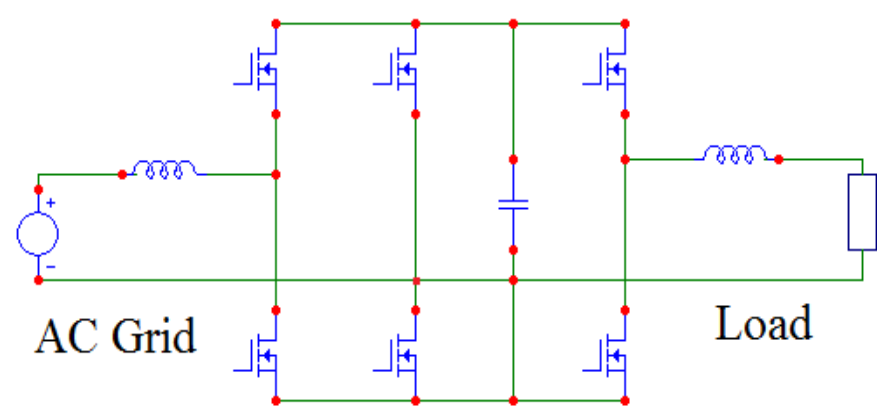

Figure 8: Three-leg AC-AC converter

Another candidate circuit is the shunt-series AC- AC converter shown in Figure 9. This topology is a combination of two voltage source converters; the first one is connected as a shunt current source in parallel with the supply and the second one in series with the load. These two VSCs can optionally be connected together via their DC-links using an isolated DC-DC converter as shown in Figure 9 or can operate as two independent converters each one with its own DC capacitor.

A variation of this circuit uses low-voltage series connected H-bridge modules, which results in reduced losses and also has the ability to provide non-galvanic isolation protection between the high and low-voltage side of the converter.

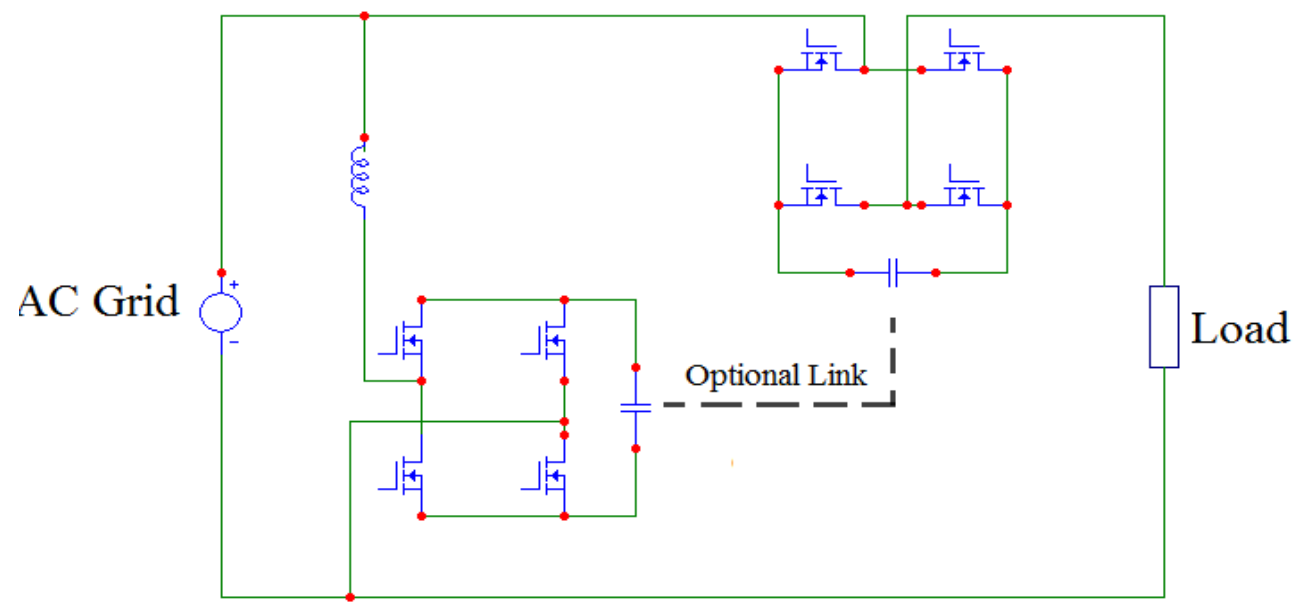

Figure 9: Shunt-Series AC-AC converter 
If the circuits described above represent the highest performance in terms of power quality, then the AC chopper shown in Figure 10 is a an example of low performance device [8]; however it is a nearoptimum solution in terms of voltage step-down capability in the context of reduced converter size, weight and co0ntrol complexity. In terms of power quality, the basic chopper circuit only provides a regulated, sinusoidal voltage to the load.

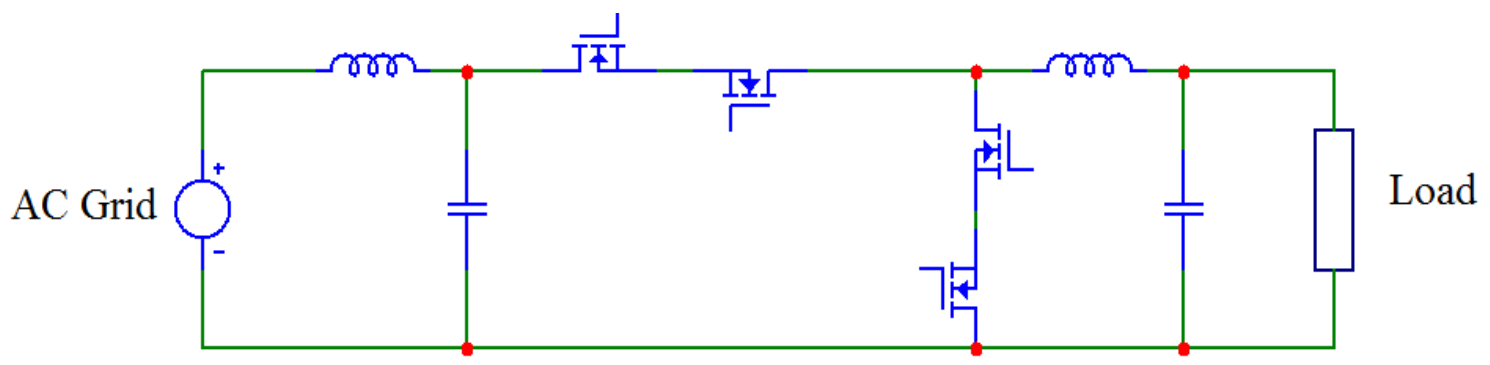

Figure 10: AC chopper converter

\section{Comparison of Converter topologies}

The converter topologies presented in the previous section (figures 7-10) were compared in terms of the switching device conduction and switching losses for three different semiconductor technologies Si MOSFETs, IGBTs and SiC MOSFETs. The ratings of other components such as capacitors and inductors were approximately equal for all the candidate circuits. Device losses were initially calculated using the Matlab/Simulink PLECS toolbox and checked against analytic expressions - for example conduction loss equations [9]. However, the severe reverse recovery losses associated with the body-diode of high-voltage MOSFETs, which were calculated by the simulation did not give satisfactory results. Therefore the simulations were carried out with Micro-Cap Spice using device manufacturers' Spice models.

The initial simulation showed that due to the constant on-state voltage characteristic of IGBTs, the resulting conduction losses meant that they were unable to meet the efficiency requirements of the converter even if the devices were to be connected in parallel. Next it was found that Si MOSFETs were also unsuitable for this application due to the high-switching losses which arise from the poor reverse recovery characteristics of the body-diode in $600 \mathrm{~V}$ rated devices. However, low voltage $\mathrm{Si}$ MOSFETs can be used in a series-connected, multi-modular version of the shunt-series converter (Figure 9), which will be presented in a future paper. The only viable semiconductors switches were found to be SiC MOSFETs, in particular the Cree CMF20120 - this is a TO247 device having an $80 \mathrm{~m} \Omega$ headline on-state resistance. Therefore, to get the required efficiency for a $15 \mathrm{~kW}$ converter meant that these devices would have to be connected in parallel or the converter would have to be divided into lower-rated, parallel sub-modules. The latter solution was chosen as it gave the opportunity to interleave the switching of individual modules $[10,11]$, which gives the benefit of a higher overall switching frequency for the converter. The optimum rating of the sub-modules, which gave the highest overall total, converter efficiency was found to be around $1 \mathrm{~kW}$. The results of the simulation studies with a $50 \mathrm{kHz}$ switching frequency are shown in Table 1, where the losses have been calculated for the complete $15 \mathrm{~kW}$ converter: 
Table 1: Total converter semiconductor losses (switching and conduction) based on 15-off, $1 \mathrm{~kW}$, $50 \mathrm{kHz}$, SiC MOSFET based sub-modules

\begin{tabular}{|l|l|c|}
\hline Converter Topologies & \multicolumn{1}{|c|}{ Comments } & \multicolumn{1}{|c|}{$\begin{array}{c}\text { Total converter } \\
\text { semiconductor losses (W) }\end{array}$} \\
\hline Two - leg (figure 7) & $\begin{array}{l}\text { High PQ benefits, complex control, high } \\
\text { DC-link voltage, 4-off Cree CMF20120 } \\
\text { MOSFETs per sub-module }\end{array}$ & 244 \\
\hline Three-leg (figure 8) & $\begin{array}{l}\text { High PQ benefits, complex control, 6- } \\
\text { off Cree CMF20120 MOSFETs per sub- } \\
\text { module }\end{array}$ & 189 \\
\hline AC Chopper (figure 10) & $\begin{array}{l}\text { Low PQ benefits, simple control, no } \\
\text { DC-link capacitor, 4-off Cree } \\
\text { CMF20120 MOSFETs per sub-module }\end{array}$ & 148 \\
\hline
\end{tabular}

Table 1 shows that the best candidate topologies in terms of efficiency are the three-leg and AC chopper circuits. However, the power quality benefits of the three-leg converter are much better than those of the AC chopper, whereas the AC chopper has a very simple control, the lowest losses, the lowest number of devices and it does not require a DC-link capacitor. Nevertheless the primary objective for the project was to demonstrate the feasibility of installing a power electronic converter into the meter box of a house and since the AC chopper has the lowest losses and number of devices it was decided that the chopper should be studied further.

\section{AC Chopper design}

Since the chopper consists of the series connection of MOSFETs, the gate drive signals must provide both a dead-time between the upper and lower devices, as well as a conduction path for the freewheeling currents for the circuit inductors. This requires a four-step transition for the four switches as the PWM signal changes state as discussed in [12], and requires the sign of the chopper output inductor current as an input to the PWM generator circuit. The switching strategy was implemented as a state-machine - Figure 11 - in Altera Quartus software, which was then used to program an Altera CPLD.

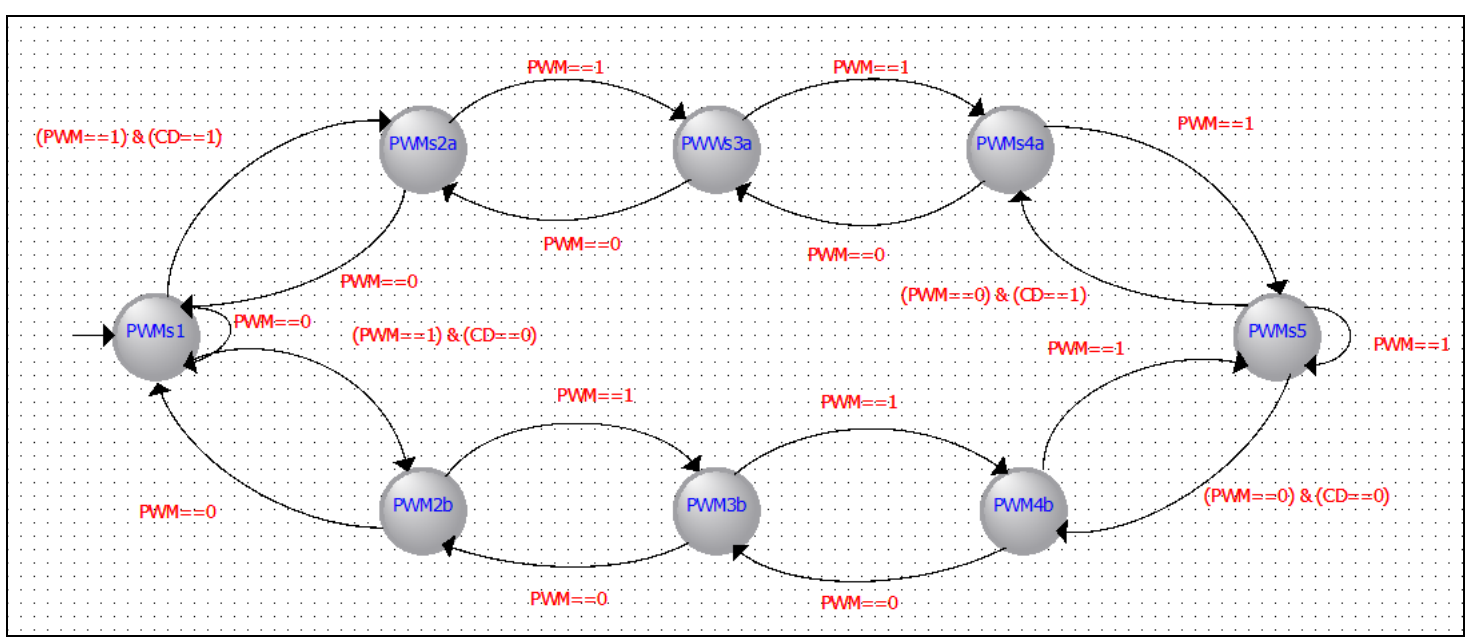

Figure 11: State-machine representation of the AC chopper PWM control. 
The state machine takes in the raw, fixed-duty cycle PWM signal (PWM in Figure 11), as well as the sign of the output inductor current (CD in Figure 11), and each state PWM1PWM5 outputs the four gate signals to the four devices [12]. Figure 12a shows the four gate signal for an upper off/lower on to upper on/lower off transistion and Figure $12 \mathrm{~b}$ its complement for positive output inductor current.

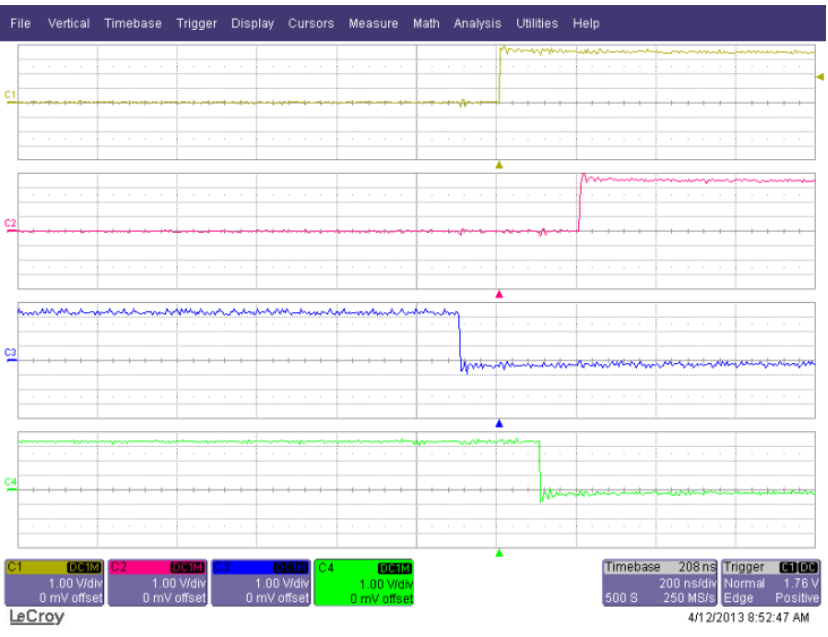

(a)

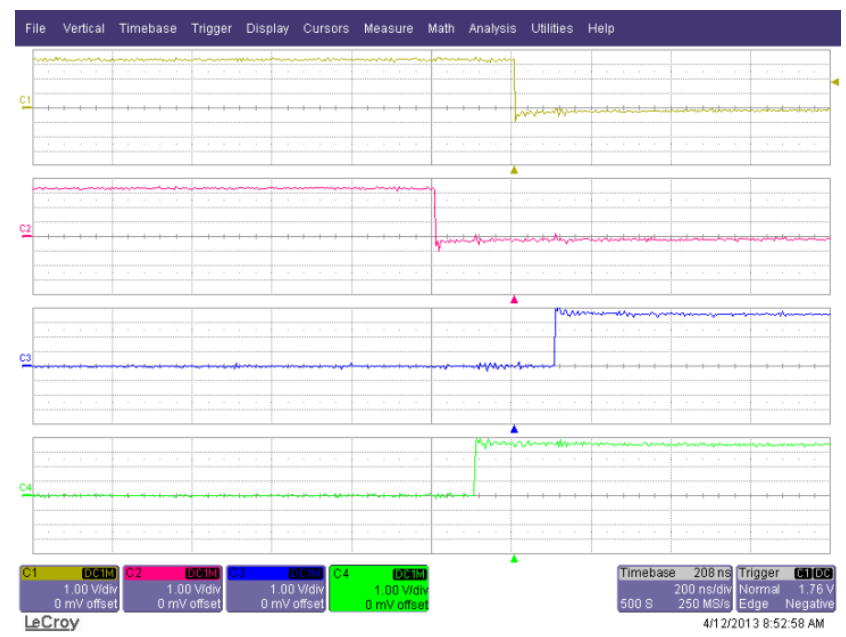

(b)

Figure 12 (a) upper devices off/lower devices on $\rightarrow$ upper devices on/lower devices off transition and (b) the complementary transition, with positive output inductor current.

The PWM converter control was validated using a low-rated, Si MOSFET based chopper and the chopper input current and output voltage are shown in Figure 13 when operating at a switching frequency of $10 \mathrm{kHz}$ and an output power of $600 \mathrm{~W}$.

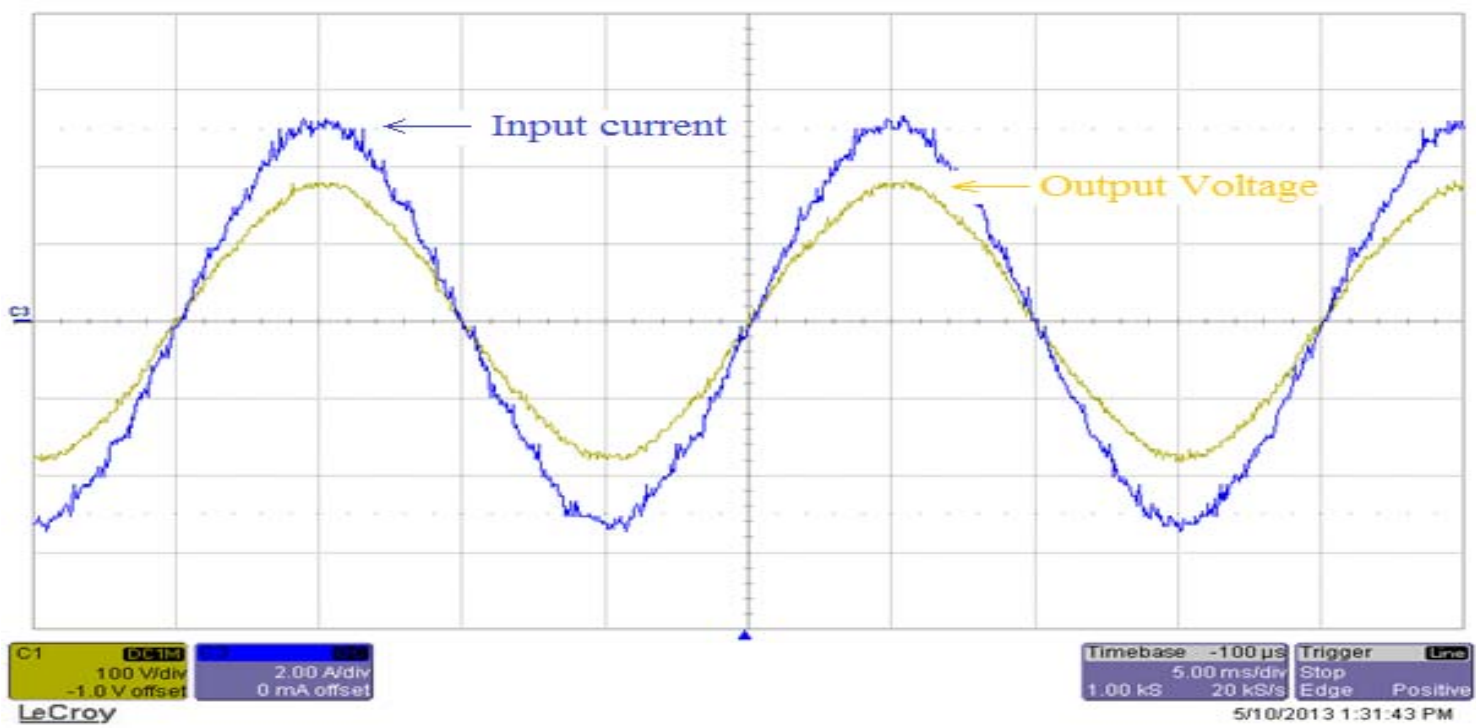

Figure 13: Input current in 2A/division and Output voltage in $100 \mathrm{~V} /$ division 


\section{Conclusions}

This paper discusses the application of a power electronic converter with a voltage step-down capability for residential loads. This device also provides an opportunity for power quality improvements in LV residential networks. The converter design is severely constrained by the environment in which it is to be installed requiring a highly-efficient converter, with total losses of less than $150 \mathrm{~W}$. Candidate circuit topologies have been identified, and simulation studies have been carried out using Micro-Cap Spice software in order to estimate the converter losses and hence the VA rating of the semiconductors. As an example Table 1 shows the total semiconductor losses for each of the candidate topologies based on Cree CMF20120 SiC MOSFETs and 15, $1 \mathrm{~kW}$ parallel submodules. IGBTs and high-voltage Si MOSFETs where found to be unsuitable for the highefficiency requirement of this project due to conduction and reverse recovery losses respectively. The objective now is to build a $\mathrm{SiC}$ based prototype and demonstrate the viability of locating such a converter in the meter-box of a house. In addition the project will also be considering emerging SiC BJT devices to further improve the efficiency of the converter.

\section{References}

[1] M.C. Benhabib, J.M.A. Myrzik, J.L. Duarte, "Harmonic effects caused by large scale PV installations in LV network", Electrical Power Quality and Utilisation EPQU 2007, pp. 1-6, 2007

[2] J. Desmet, G. Vanalme, C. Debruyne, L. Vandevelde, "Influence of harmonic currents on cable losses for different grid configurations", Harmonics and Quality of Power (ICHQP), pp. 1-6, 2010

[3] A. Ghosh and G. Ledwich, "A unified power quality conditioner (UPQC) for simultaneous voltage and current compensation,", Electric Power Systems Research, Vol. 59, pp. 55-63, 2001

[4] Rabkowski, J.; Peftitsis, D.; Nee, H-P, "Design steps towards a 40-kVA SiC inverter with an efficiency exceeding 99.5\%," Applied Power Electronics Conference and Exposition (APEC), 2012 Twenty-Seventh Annual IEEE , vol., no., pp.1536,1543, 5-9 Feb. 2012

[5] C. Ling; B. Ge; D. Bi; Q. Ma, "An effective power electronic transformer applied to distribution system", Electrical Machines and Systems (ICEMS), pp.1-6, 2011

[6] Jacobina, C.B.; de Freitas, I.S.; da Silva, E.R.C.; Lima, A.M.N.; de Oliveira, T.M.; , "AC-AC singlephase to single-phase two-leg converters," Industry Applications Conference, 2005. Fourtieth IAS Annual Meeting. Conference Record of the 2005 , vol.4, no., pp. 2388- 2394 Vol. 4, 2-6 Oct. 2005.

[7] Han-Woong Park; Sung-Jun Park; Jin-Gil Park; Cheul-U Kim; , "A novel high-performance voltage regulator for single-phase AC sources," Industrial Electronics, IEEE Transactions on, vol.48, no.3, pp.554-562, Jun 2001

[8] K. Samidurai, G. Ilango, K. Thanushkodi, "Performance comparison of single-phase power electronic controllers", Power Engineering and Optimization Conference (PEOCO), pp. 107-111, 2010

[9] Mestha, L.K.; Evans, P.D.; , "Analysis of on-state losses in PWM inverters," Electric Power Applications, IEE Proceedings B, vol.136, no.4, pp.189-195, Jul 1989

[10] Zhang, M.T.; Jovanovic, M.M.; Lee, F.C.Y., "Analysis and evaluation of interleaving techniques in forward converters," Power Electronics, IEEE Transactions on , vol.13, no.4, pp.690,698, Jul 1998

[11] Gerber, M.; Ferreira, J.A.; Hofsajer, I.W.; Seliger, N., "Interleaving optimization in synchronous rectified DC/DC converters," Power Electronics Specialists Conference, 2004. PESC 04. 2004 IEEE 35th Annual , vol.6, no., pp.4655,4661 Vol.6, 20-25 June 2004

[12] Burany, N., "Safe control of four-quadrant switches," Industry Applications Society Annual Meeting, 1989., Conference Record of the 1989 IEEE, vol., no., pp.1190,1194 vol.1, 1-5 Oct. 1989 